\title{
Loneliness and Anxiousness as Predictors of Facebook use among College Students
}

\section{Aleli M. Langgaman}

\author{
Kalinga State University, Philippines
}

Received: 27 Sep 2020; Received in revised form: 09 Dec 2020; Accepted: 19 Dec 2020; Available online: 31 Dec 2020

(C)2020 The Author(s). Published by Infogain Publication. This is an open access article under the CC BY license

(https://creativecommons.org/licenses/by/4.0/).

\begin{abstract}
Social Networking Sites (SNS), such as Facebook, have been attracting so many users worldwide by offering virtual communications to its users. Thus, the study examined if loneliness and anxiousness would predict Facebook use among college students. A survey of 365 participants who are active Facebook users was conducted at Kalinga State University. The study examined the predictor variables: loneliness and anxiousness in relation to the Facebook Intensity Scale (Ellison et al. 2007). The two predictor variables were examined using a linear regression model and results showed that college students have moderate levels of loneliness, anxiousness and Facebook use. Furthermore, loneliness has a weak positive relationship with Facebook use while anxiousness has no relationship with Facebook use. Lastly, it was also found that loneliness contributes to Facebook use among college students. The study adds to the increasing body of literature investigating why individuals develop an emotional attachment to Facebook and the precursors of why people are drawn to connect in Facebook.
\end{abstract}

Keywords-loneliness, anxiousness, facebook use, college students.

\section{INTRODUCTION}

During the last decade, the use of social media and social networking sites (SNSs) has increased enormously facilitated by the rising availability of mobile Internet and smartphones. This innovation has made a great impact in the lifestyle of people especially in the aspect of communication. People can already converse with others even if they are miles away just by pressing their phones or using any other gadgets that connects to the Internet. With the convenience that these social networking sites are providing the public, people are immersed tremendously with the use of it.

The most popular of the Social Networking Sites (SNSs), Facebook, has now more than 1 billion active users. Like other SNSs, Facebook enables users to create visible profiles. According to Ellison et al. (2007), Facebook enables its users to present themselves in an online virtual profile, accumulate friends with whom they can chat online, post comments on each other's pages, create and join virtual social groups, and view others' profiles. When viewing others'
Facebook profiles, users can learn about others' personal information and other private knowledge the account owner has chosen to share like hobbies, interests, and romantic relationship statuses. With more than 2 billion monthly active users, Facebook is considered the most popular social network worldwide. It is ranked as the most used site among university students to the point that it would be difficult to find students who were not Facebook users (Lenhart et al., 2010). The more interesting fact is that $78 \%$ of the Facebook users, between the age group of 18-34 check Facebook every time they woke up or got out of bed (Statistics Brain).

Along with those, Keenan and Shiri (2009) found that voyeurism can also explain the Facebook usage of students. This concept explains that use of Facebook is mostly in watching videos and photos of other users. Moradabadi, et al., (2012) also found that the main motivating factors for using Facebook was to share information, freedom of communication, free flow of information, control of 
information, principles of equality and the need for information and entertainment.

These features of SNS specially Facebook are the main reasons why people are very drawn in using it. In Kalinga State University, students are observed to be engaged in different social media platforms and one of those is Facebook. With their mobile phones constantly with them, students are able to connect to others virtually, they are able to get information online, and they are able to update themselves with the trends of society. With the constant use of students of Facebook, it is interesting to find out the reasons for their engagement. Many studies have reported that SNS can be a useful resource of students to cope with feelings of alienation and anxiety which are commonly experienced by adolescents specially during their college years.

Loneliness and anxiousness are two common feelings people experience which may have contributed to the feeling of attachment of people to Facebook. According to Masi, et. al. (2011), Feeling of loneliness is subjective. It is the interpretation that an individual gives to his own reality. This means that a person can feel lonely even if she is surrounded by people or can feel satisfied even if she is with a smaller number of social ties. A feeling of loneliness directs us to seek gratifying social interactions and avoid unsatisfying social interactions.

Prior researches have produced mixed findings regarding the impact of technology, especially online social networks and social media, on feelings of loneliness. Lemieux, Lajoie, \& Trainor (2013) found that college students who posted more status updates than they normally did felt less lonely over the course of a week. And a drop in loneliness was linked to an increase in feeling more socially connected, which the researchers believe is the cause behind the positive effects of status updating. Pempek et al.'s (2009) findings suggest that students may use Facebook as a source of communication with only friends or family members who are not in their new environment in order to continue to feel connected with others so as to eliminate their feelings of loneliness. Lou (2010) found similar results, which suggest that time spent on Facebook helps aids in reducing feelings of loneliness when in new environments. Individuals who are experiencing feelings of loneliness are drawn to the interpersonal advantages offered by online social networks, which in turn can lead to problematic outcomes (Kim, LaRose,\& Weng, 2009).
Anxiety, on the other hand, is an emotion characterized by feelings of tension, worried thoughts and physical changes like increased blood pressure. People with anxiety disorders usually have recurring intrusive thoughts or concerns. They may avoid certain situations out of worry (American Psychological Association, 2008). Studies have also shown the relationship between anxiety feelings and Facebook use. Kalpidou, Costin, and Morris (2011) found that students who were observed to be socially anxious were also observed being on Facebook more often than other students in the program. Those who were observed as being socially anxious were quick to add fellow classmates on Facebook. However, those who did not appear to be socially anxious were not eager to become friends with classmates on the networking site.

In a common scenario, college students may be likely to experience feelings of anxiousness (Ozdemir \& Tuncay, 2008). These feelings may be a result from experiencing homesickness, which occurs when a person has left behind a well-developed and well-attached social support network and has ensuing difficulty adapting to a new environment (Beck, Taylor, \& Robbins, 2003). The social networking site, Facebook, can be a useful resource to cope with these feelings of alienation by establishing and maintaining connections with others (Ellison et al., 2007).

Sheldon (2008) found that people who are socially anxious like to use Facebook to reduce emotional stressors, such as loneliness. Individuals are often motivated by a need to belong; however, those who are socially anxious may find it difficult to fulfil this social need in real world social contexts, that is why they turn into social networking sites (Raacke, 2008). These outcomes may stem from the fact that shy and socially anxious people tend to feel more comfortable maintaining social relationships in online settings than they do in face-to-face interactions (Ebeling-Witte et al., 2007). Similarly, a recent study found that shyness, similar to anxiousness, was significantly positively correlated with the time spent on Facebook and resulted in favorable attitudes towards Facebook (Orr et al., 2009). And Hagin et al. (2010) found that those who are socially anxious use Facebook for companionship more than those who are less socially anxious. Provided with the ability to socialize online, rather than engaging in face-to-face interactions, socially anxious individuals are more likely to develop relationships online (McKenna, Greene, \& Gleason, 2008).

Thus, the study particularly aims to determine if the prevalence of Facebook use among college students were 
caused by their experience of loneliness or anxiousness. It examined if loneliness and anxiousness would predict Facebook use among college students of Kalinga State University. It determined the degree of experience of loneliness among the college students; it determined the relationship between the degree of loneliness and the intensity of facebook use; it determined which of the two variables (loneliness or anxiousness) better predict an intensity of facebook use.

\section{METHODOLOGY}

The locale of the study was in Kalinga State University. The researcher used the Slovin's Formula to determine the sample size. Participants were active users of Facebook and all participants were tasked to answer the three questionnaires: UCLA Loneliness Scale, Social Interaction Anxiety Scale and Facebook Intensity Scale.

Loneliness was measured by the UCLA Loneliness scale (Russel, D, Peplau, L.A.; Ferguson, M.L. 1996). It is developed to measure the students' perceived levels of loneliness in their recent experience. It includes 20 items. Evidence of discriminant and construct validity for the UCLA Loneliness scale has been provided by past research examining the scale. Data will be gathered using a Likert-type scale anchored by $1=$ Never and $5=$ Always.

Anxiety was measured by the Social Interaction Anxiety Scale (Mattick, R. P., \& Clarke, J. C. 1998). It is a 20 item self-report scale designed to measure social interaction anxiety defined as "distress when meeting and talking with other people". This tool is helpful in tracking social anxiety symptoms over time, and may be helpful as part of an assessment for social phobia or other anxiety related disorders. Data were gathered using a Likert-type scale anchored by $1=$ not at all characteristic of me and $5=$ Extremely characteristic of me.

Intensity of Facebook use was measured by the Facebook Intensity scale (Ellison, N.B., Steinfield, C., \& Lampe, C. 2007). Data were gathered using a Likert-type scale anchored by $1=$ Strongly Disagree and 5=Strongly Agree.

For the analysis of the data, the Mean (X) was used to measure the degree of experience of loneliness, degree of experience of anxiousness, and the intensity of Facebook use among college students. The Pearson Correlation Coefficient ( $r$ ) was used to measure the relationship between the degree of loneliness and the intensity of Facebook use as well as the ISSN: 2456-7620 relationship between the degree of anxiousness and the intensity of Facebook use. The Multiple Regression Analysis $(R)$ was used to measure the relationship among the three variables (loneliness, anxiousness and Facebook use) as well as to know the better predictor for Facebook use.

\section{RESULTS AND DISCUSSIONS}

The mean obtained for the degree of experience of loneliness among college students was 2.5650. This indicates that there is a moderate degree of loneliness among college students. For the degree of experience of anxiousness among college students, the obtained mean was 2.94. This indicates that there is a moderate degree of anxiousness among college students. For the intensity of Facebook use among college students, the obtained mean was 2.9398. This indicates that there is a moderate intensity of Facebook use among college students.

Results from the Pearson Correlation showed that: the correlation between the degree of loneliness and the intensity of Facebook use was found to be significant, $r=.224$, $\mathrm{p}<.001$. Loneliness showed a weak positive relationship with the intensity of Facebook use. The relationship between the degree of anxiousness and the intensity of Facebook use was found to be insignificant, $r=.071, p>.001$. The Multiple Correlation Coefficient was .226, indicating that 5\% of Facebook use is explained by loneliness and anxiousness.

Results from the Stepwise Multiple Regression Analysis showed that loneliness entered into the regression equation and was significantly related to Facebook use $\mathrm{F}$ $(1,98)=5.170, \mathrm{p}<.001$. The determination coefficient was .05 , indicating approximately $5 \%$ of Facebook use is explained by Loneliness. It is relatively small but still it contributes to Facebook use.

Results from the Means show that there is a moderate degree of loneliness, anxiousness and Facebook use among college students.

Researchers have indicated that adolescents experience more loneliness than any other age group. For many university students, this may be the first time they live away from their parents. They may move away from the emotional and social support of their families. The separation of college students from their homes for the first time may create feelings of doubt, confusion, and loneliness. Weiss stated that individuals who are unable to attach to other individuals will feel themselves lonely. But because of several activities, students can resist their feeling of 
loneliness. These activities would include watching TV, surfing the Internet and hanging out with their friends.

Additionally, anxiety are prevalent problems in colleges across the country. The level of anxiety that arise from college students are primarily from the effect of trying to juggle school, work, friends, and family while trying to figure out the rest of their lives. Ramon Jimenez, a personal counselor at El Paso Community College (EPCC) says that "College students of all ages nowadays have so many responsibilities; they go into anxiety mode at school, and then it stays on while they're working or studying, and they're stuck in it by the time they get home to their families."

The moderate intensity of Facebook use is consistent with the study of Ellison et al. (2007) that students experience social adjustment which refers to having a feeling of fitting in with the college community and being satisfied with established social connections and the social activities offered on campus.

Results from the Pearson Correlation showed that loneliness has a weak positive relationship with the intensity of Facebook use while anxiousness showed no or negligible relationships with the intensity of Facebook use.

This finding suggests that lonely individuals would engage into Facebook to connect with others to reduce their loneliness, which is similar to the findings established by Lou (2010). Pempek 40 et al.'s (2009) study who found out that students use Facebook the most to communicate with friends who are not on campus, such as high school friends or family members to reduce their loneliness.

Individuals who suffer from anxiety and low selfesteem have a lot to gain from using SNS. Yet, paradoxically, these individuals are less likely to do so. One study in particular found that online social communication skills and self-esteem are correlated, indicating a link between the strength of offline relationships and time spent online; this might not work to the advantage of socially anxious individuals for whom offline relationships are difficult to forge in the first place (Jacobsen \& Forste, 2011). One explanation is that websites like Facebook may unintentionally favor individuals with pre-existing close relationships rather than those who do not have close relationships to begin with (Ellison et al., 2007). Furthermore, even if it is possible for SNS to aid people suffering from social anxiety and low self-esteem by providing them with an opportunity to establish new relationships at a diminished cost of entry, the formation of weak ties does not necessarily translate into the kind of relationships that psychologists associate with social bonding.

Results from the Multiple Regression Analysis showed that loneliness was the better predictor of Facebook use. It is found that loneliness contributes to Facebook use.

Lonely individuals have trouble connecting and forming warm relationships as well as finding emotional support (Heinrich \& Gullone, 2006). As a result, individuals may become dependent on Facebook as a way to find social connections. Consequently, individuals may turn to Facebook because they use it as a way to find emotional support and relieve their loneliness. Adolescents who feel lonely in their relationship with peers were more likely to use Facebook to compensate for their weaker social skills, to diminish their feelings of loneliness, and to have more interpersonal contact. These findings suggest that adolescents who are lonely towards peers will especially use Facebook to feel more comfortable in making social contact (Teppers et al. 2013).

\section{CONCLUSIONS}

College students experience loneliness and anxiousness. Likewise, they engage themselves to Facebook use. Although college students experience anxiousness, this does not explain their usage of Facebook. The loneliness which students experience has little contribution to Facebook use. Loneliness can somehow predict Facebook use but it is not the main reason why college students use Facebook.

\section{RECOMMENDATIONS}

The study found that Facebook use can be explained by loneliness. Thus, developing effective interventions to reduce feelings of loneliness of students may be of effect. School administration, teachers and the guidance personnel should work hand in hand to come up with a plan on how to put students in a comfortable condition. Additionally, the guidance office has to approach students to prevent and decrease loneliness by strengthen existing relationships. Future research should also be conducted to find out the other predictors of Facebook use among college students.

\section{REFERENCES}

[1] Cheung, C. M., Chiu, P. Y., \& Lee, M. K. (2011). Online social networks: Why do students use facebook?.computers in Human Behavior, 27 (4), 1337-1343 
[2] Ebeling-

Witte, S., Frank, M. L., \& Lester, D. (2007). Shyness, internet use, and personality. CyberPsychology and Behavior, 10, 713-716

[3] Ellison, N., Steinfield, C.,\&Lampe, C. (2007). The benefits of Facebook friends: Social capital and college students' use of online social network sites. Journal of Computer Mediated Communication, 12, 1143-1168

[4] Hagin, E., Abree, R., Jivani, A., \& Tunick, D. (2010). Social anxiousness and Facebookuse: Exploring the uses and gratifications of social networking in sociallyanxious individuals. Unpublished manuscript

[5] Kalpidou, M., Costin, D., \& Morris, J. (2011). The relationship between Facebook andthe wellbeing of undergraduate college students. Cyberpsychology, 14 ,183-189

[6] Keenan, A., \& Shiri, A. (2009). Sociability and social interaction on social networking websites.

[7] Library Review, 58 (6), 438-450

[8] Lenhart, A., Purcell, K., Smith, A., \& Zickuhr, K. (2010b). Social media and young adults. Washigton, DC: Pew Internet and American Life Project

[9] Moradabadi, Y. N., Gharehshiran, M. A., \& Amrai, K. (2012). What is the Motivation Student of Iranians for using Facebook?. Procedia-Social and Behavioral Sciences, 46, 5192-5195

[10] Lou, L. L., Zheng, Y., Nickerson, A., \& McMorris, R. (2012). Examination of th ereciprocal relationship of loneliness and Facebook use among first-yearcollegestudents. Journal of Educational Computing Research, 46, 105-117

[11] Masi, C. M., Chen, H. Y., Hawkley, L. C., \& Cacioppo, J. T. (2011). A meta-analysis of interventions to reduce loneliness. Personality and Social Psychology Review, 15(3), 219-266. https://doi.org/10.1177/1088868310377394

[12] McKenna, K., \& Bargh, J. (2000). Plan 9 from cyberspace. The implications of theinternet for personality and social psychology. Personality and Social PsychologyReview, 4, 57-75

[13] Orr,E.S.,Sisic,M., Ross,C.,Simmering,M.G.,Arsenault,J.M.,\& Orr,R.R.(2009).Theinfluence of shyness on the use of facebook in an undergraduate sample. Cyber Psychology and Behavior, $12,337-340$

[14] Ozdemir, U., Tunkay, T. (2008). Correlates of Loneliness among College students. PMC. Retrieved from http://www.ncbi.nlm.nih.gov/pmc/articles/PMC2572161/

[15] Pempek, T., Yermolayeva, Y., \& Calvert, S. (2009). College s tudents' socialnetworking experiences on Facebook. Journal of Applied DevelopmentalPsychology, 30, 227-238

[16] Raacke, J., \&Bonds-Raacke, J. (2008). My Space and Facebook: Applying the uses ndgratifications theory to exploring friend-networking sites. Individual Differences Research Group, 8, 27-33
[17] Russell, D. W. (1996). UCLA Loneliness Scale (Version 3): Reliability, validity, and factor structure. Journal of Personality Assessment, 66 , 20-40.

[18] Sheldon, P. (2008). The relationship between unwillingnessto-communicate and students' Facebook use. Journal of Media Psychology, 20, 67-75

[19] "Statistics Brain", Accessed from http://www. statisticbrain.com/Facebook statistics, Accessed on December 05,2013 